\title{
Impacts of discriminated $\mathrm{PM}_{2.5}$ on global under-five and maternal mortality
}

\author{
Patrick Opiyo Owili ${ }^{1}$, Tang-Huang Lin ${ }^{2 \bowtie}$, Miriam Adoyo Muga ${ }^{3} \&$ Wei-Hung Lien ${ }^{2}$
}

Globally, it was estimated that maternal and under-five deaths were high in low-income countries than that of high-income countries. Most studies, however, have focused only on the clinical causes of maternal and under-five deaths, and yet there could be other factors such as ambient particulate matter (PM). The current global estimates indicate that exposure to ambient $\mathrm{PM}_{2.5}$ (with $\leq 2.5$ microns aerodynamic diameter) has caused about 7 million deaths and over 100 million disability-adjusted life-years. There are also several health risks that have been linked $\mathrm{PM}_{2.5}$, including mortality, both regionally and globally; however, $\mathrm{PM}_{2.5}$ is a mixture of many compounds from various sources. Globally, there is little evidence of the health effects of various types of $\mathrm{PM}_{2.5}$, which may uniquely contribute to the global burden of disease. Currently, only two studies had estimated the effects of discriminated ambient $\mathrm{PM}_{2.5}$, that is, anthropogenic, biomass and dust, on under-five and maternal mortality using satellite measurements, and this study found a positive association in Africa and Asia. However, the study area was conducted in only one region and may not reflect the spatial variations throughout the world. Therefore, in this study, we discriminated different ambient $\mathrm{PM}_{2.5}$ and estimated the effects on a global scale. Using the generalized linear mixed-effects model (GLMM) with a random-effects model, we found that biomass $\mathrm{PM}_{2.5}$ was associated with an $8.9 \%$ (95\% confidence interval $[\mathrm{Cl}]$ 4.1-13.9\%) increased risk of under-five deaths, while dust $\mathrm{PM}_{2.5}$ was marginally associated with $9.5 \%$ of under-five deaths. Nevertheless, our study found no association between $\mathrm{PM}_{2.5}$ type and global maternal deaths. This result may be because the majority of maternal deaths could be associated with preventable deaths that would require clinical interventions. Identification of the mortality-related types of ambient $\mathrm{PM}_{2.5}$ can enable the development of a focused intervention strategy of placing appropriate preventive measures for reducing the generation of source-specific $\mathrm{PM}_{2.5}$ and subsequently diminishing $\mathrm{PM}_{2.5}$-related mortality.

In 2017, it was estimated that the daily maternal deaths (i.e., during pregnancy and childbirth) were over 800 , with most of these deaths occurring in low- and middle-income countries (LMICs). The global variation in the maternal mortality ratio between high-income (11 deaths per 100,000 live births) and low-income countries (462 deaths per 100,000 live births) was noticeable, and this highlights the differences between the rich and the poor countries in terms of health outcomes. Moreover, the lifetime risk of maternal death was equally high in low-income countries ( 1 death in 45 women) than in high-income countries ( 1 death in 5400 women $)^{1}$. These high maternal death rates in LMICs was also reflected in the deaths of the under-five children, which is estimated to be high in some regions like the Sub-Saharan Africa (SSA, 76 deaths per 1000 live births) as compared to that of other regions like the European region ( 9 deaths per 1000 live births) in $2018^{2}$. Nevertheless, most studies on the maternal and under-five deaths are mainly clinically-focused, and yet these deaths might not only be a result of clinical factors such as postpartum hemorrhage and eclampsia. Other factors such as environmental causes like ambient particulate matter (PM) could be related.

The current global estimates indicate that exposure to ambient $\mathrm{PM}_{2.5}$ (with $\leq 2.5$ microns aerodynamic diameter) has caused about 7 million deaths and over 100 million disability-adjusted life-years ${ }^{3}$. There are also several health risks that have been linked to $\mathrm{PM}_{2.5}$, including mortality, both regionally and globally ${ }^{3-6}$; however, $\mathrm{PM}_{2.5}$ is a mixture of many compounds from various sources. Globally, there is little evidence of the health effects of discriminated $\mathrm{PM}_{2.5}$ (i.e., the major component of $\mathrm{PM}_{2.5}$ ), which may uniquely contribute to the global burden

${ }^{1}$ Department of Public Health, School of Health Sciences, University of Eastern Africa, Baraton, Eldoret, Kenya. ${ }^{2}$ Center for Space and Remote Sensing Research, National Central University, Taoyuan City, Taiwan. ${ }^{3}$ Department of Human Nutrition and Dietetics, School of Medicine and Health Sciences, Kabarak University, Kabarak, Kenya. ${ }^{\varpi}$ email: thlin@csrsr.ncu.edu.tw 
of disease. Currently, there are limited studies that have estimated the effects of discriminated or categorized ambient $\mathrm{PM}_{2.5}$, that is, anthropogenic, biomass and dust, on under-five and maternal mortality using satellite measurements, and these studies found a positive association in Africa ${ }^{5}$ and Asia ${ }^{7}$. However, these studies ${ }^{5,7}$ were regional and may not reflect the spatial variations throughout the world. Therefore, in this study, we discriminated ambient $\mathrm{PM}_{2.5}$ and estimated the effects on a global scale. Using the generalized linear mixed-effects model (GLMM) with a random-effects model, we found that biomass $\mathrm{PM}_{2.5}$ was associated with an $8.9 \%(95 \%$ confidence interval [CI] 4.1-13.9\%) increased risk of under-five deaths, while dust $\mathrm{PM}_{2.5}$ was marginally associated with $9.5 \%$ of under-five deaths. Nevertheless, our study found no association between $\mathrm{PM}_{2.5}$ type and global maternal deaths. This result may be because the majority of maternal deaths could be associated with preventable deaths that would require clinical interventions. Identification of the mortality-related types of ambient $\mathrm{PM}_{2.5}$ can enable the development of a focused intervention strategy of placing appropriate preventive measures for reducing the generation of source-specific $\mathrm{PM}_{2.5}$ and subsequently diminishing $\mathrm{PM}_{2.5}$-related mortality.

Studies have indicated that sources of $\mathrm{PM}_{2.5}$ may vary and are likely to contribute to the accumulation of various toxic compounds that are suspended in the air, such as sulphur oxides $\left(\mathrm{SO}_{\mathrm{x}}\right)$, carbon monoxide $(\mathrm{CO})$, particulates, and nitrogen oxides $\left(\mathrm{NO}_{\mathrm{x}}\right)^{8-10}$, which may then contribute to various health problems and subsequently an increase in the global burden of disease. Policy makers have also set global no-threshold limits for exposure to ambient $\mathrm{PM}_{2.5}$ (i.e., daily exposure less than $25 \mu \mathrm{g} / \mathrm{m}^{3}$ while annual exposure less than $\left.\leq 10 \mu \mathrm{g} / \mathrm{m}^{3}\right)^{9}$; yet, there is still an ongoing discussion of the need to harmonize ambient air quality standards since these standards vary greatly among regions and countries ${ }^{11,12}$. From these discussions, questions have also arisen as to whether each country or each region should set its own air quality standards. Nevertheless, harmonizing the national and global air quality standards may still be an issue and a challenge worthy of discussion since the point sources of ambient $\mathrm{PM}_{2.5}$ vary from place to place. Therefore, ambient $\mathrm{PM}_{2.5}$ may be linked to a variety of elements suspended in the air in different areas, which may have diverse health effects. Several authors, however, developed a modest method for identifying and quantifying different ambient $\mathrm{PM}_{2.5}$ types that are suspended in the airr ${ }^{13}$, and this method has been applied to study the types of ambient $\mathrm{PM}_{2.5}$ and mortality in Africa ${ }^{4}$.

The types of ambient $\mathrm{PM}_{2.5}$ were measured and quantified using the same techniques, and the global effect on mortality was then estimated before a dose-response relationship in the different world regions was determined. We used the most recent satellite-based measurements of country-level annual ambient $\mathrm{PM}_{2.5}$ concentrations and country-level annual under-five and maternal mortality. Satellite data are important in this study because most low- and middle-income countries (LMICs) do not have adequate ground-based air quality monitoring sites that could provide real-time data. Several studies from LMICs have also used satellite data ${ }^{4,5}$.

Unlike one of the previous studies that focused on only the African region ${ }^{4}$, we employed the random-effects modelling technique using a generalized linear mixed-effects model (GLMM) with a spatial covariance structure, Poisson link function, natural cubic spline, and penalized quasi-likelihood (PQL) approach to adjust for the time, season and spatial variations in $\mathrm{PM}_{2.5}$ and mortality within and between different countries and regions ("Methods"). Natural spline was used as a smoothing function. The fixed-effects model is only appropriate when there is no variation between different regions or areas. However, in the case of handling global data, we expect variations between and within countries and regions; hence use of the random-effects model would provide true estimates in our analyses. The country and regional boundaries were determined before the annual means of the different types of $\mathrm{PM}_{2.5}$ and mortality were estimated for each country and each region (Methods; Table 1). The data over 16 years (i.e., 2000-2015) were analysed to determine the effects of the types of ambient $\mathrm{PM}_{2.5}$ on mortality after adjusting for potential confounders.

\section{Results and discussions}

The global frequency distributions of major $\mathrm{PM}_{2.5}$ types (Fig. 1a) were significantly different among regions, in particular heavy $\mathrm{PM}_{2.5}$ loadings occurred in North America, Central Africa, West Asia, South Asia and East Asia (Fig. 1b). The impacts on human health after long-term exposure could be distinct in each region and should be carefully considered.

A meta-analysis approach was used to estimate the global effects of the discriminated types of $\mathrm{PM}_{2.5}$ on under-five deaths (Fig. 2 and Table 2) and maternal deaths (Fig. 3 and Table 2). The results of the random-effects model for the global estimates indicated that biomass $\mathrm{PM}_{2.5}$ (Fig. $2 \mathrm{~b}$ ) was associated with an $8.9 \%$ (95\% confidence interval [CI] 4.1-13.9\%; $p<0.001$ ) risk of under-five deaths. This result is consistent with recent evidence on non-discriminated ambient $\mathrm{PM}_{2.5}$, which found a $9.2 \%$ increase in infant mortality ${ }^{4}$. Consequently, it could possibly be argued that biomass $\mathrm{PM}_{2.5}$ could have contributed to a great portion of the $9.2 \%$ increase in infant mortality in the Heft-Neal, et al. ${ }^{4}$ study. Further testing would be necessary to show this point. The annual average biomass $\mathrm{PM}_{2.5}$ levels were, however, greater than $30 \mu \mathrm{g} / \mathrm{m}^{3}$ in most of the regions (Table 1), but the risk of death increased only in Africa by $1.2 \%$, and the Americas and Asia contributed to the largest proportions at $26.0 \%$ and $48.6 \%$, respectively (Fig. $2 \mathrm{~b}$ and Table 2 ). The environmental health literature also suggests an association between biomass burning, which is used for cooking, and under-five mortality in different regions ${ }^{14,15}$.

The dust $\mathrm{PM}_{2.5}$ (Fig. 2c and Table 2) marginally increased the risk of under-five mortality by $9.5 \%(p=0.058)$. However, the increased risk of death was statistically significant in only the Americas and Asia at $23.8 \%$ and $45.9 \%$, respectively. Saharan dust events (i.e., African dust storms) inject large amounts of mineral dust into the air over the Atlantic Ocean and have been linked to the increase in $\mathrm{PM}_{2.5}$ in North America, Central America, the Caribbean and Europe in the months between June and October ${ }^{16-19}$. Our study also found that the annual mean levels of dust $\mathrm{PM}_{2.5}$ were relatively high in North America and Asia compared to other regions (Table 2). Ironically, the desert area of Northern Africa had low levels of annual mean dust $\mathrm{PM}_{2.5}\left(26.7 \mu \mathrm{g} / \mathrm{m}^{3}\right)$, possibly because larger particles settle very fast in the area, while small particles $\left(\mathrm{PM}_{2.5}\right)$ remain suspended in the air and are then transported to other regions by wind ${ }^{19}$. Dust storms are natural phenomena that are not associated with 


\begin{tabular}{|c|c|c|c|c|c|c|}
\hline & $\begin{array}{l}\text { Total countries and } \\
\text { islands }\end{array}$ & $\begin{array}{l}\text { Under-5 mortality } \\
\text { annual mean }\end{array}$ & $\begin{array}{l}\text { Maternal mortality } \\
\text { annual mean }\end{array}$ & $\begin{array}{l}\text { Biomass } \mathrm{PM}_{2.5 ;} \text { Jan-Dec } \\
\mu \mathrm{g} / \mathrm{m}^{3}\end{array}$ & $\begin{array}{l}\text { Anthropogenic } \\
\text { PM }_{2.5 ; \text { Jan-Dec }} \mu \mathrm{g} / \mathrm{m}^{3}\end{array}$ & $\begin{array}{l}\text { Dust } P_{\mu M_{2.5} \text {;an-Dec }} \\
\mu \mathrm{g} / \mathrm{m}^{3}\end{array}$ \\
\hline & $n=206$ & $n(S D)$ & $n(S D)$ & Mean, $n(S D)$ & Mean $(S D)$ & Mean $(S D)$ \\
\hline \multicolumn{7}{|l|}{ Global regions } \\
\hline \multicolumn{7}{|l|}{ Africa } \\
\hline Central Africa & 8 & $61,321(104,706)$ & $4131(6862)$ & $48.2(11.3)$ & $36.2(8.3)$ & $36.3(8.2)$ \\
\hline Eastern Africa & 13 & $68,806(81,033)$ & $4613(5546)$ & $32.7(5.9)$ & $27.4(3.6)$ & $26.8(4.2)$ \\
\hline Northern Africa & 6 & $22,022(21,939)$ & $706(473)$ & $27.3(3.3)$ & $24.9(3.6)$ & $26.7(3.9)$ \\
\hline Southern Africa & 10 & $51,982(53,012)$ & $2310(2335)$ & $29.2(3.7)$ & $23.5(3.4)$ & $21.5(2.9)$ \\
\hline Western Africa & 16 & $97,942(197,426)$ & $6061(13,375)$ & $41.8(7.7)$ & $34.9(4.8)$ & $35.2(5.1)$ \\
\hline \multicolumn{7}{|l|}{ Americas } \\
\hline Caribbean Islands & 19 & $12,401(17,562)$ & $579(817)$ & $34.1(1.6)$ & $27.7(1.5)$ & $29.1(1.3)$ \\
\hline Mesoamerica (Central) & 8 & $9309(14,544)$ & $302(404)$ & $36.7(4.0)$ & $27.3(2.2)$ & $28.7(3.9)$ \\
\hline North America & 3 & $24,185(16,365)$ & $821(786)$ & $32.1(4.0)$ & $29.5(8.3)$ & $41.1(16.7)$ \\
\hline South America & 12 & $12,854(19,641)$ & $461(541)$ & $33.1(4.9)$ & $25.4(3.8)$ & $24.7(5.8)$ \\
\hline \multicolumn{7}{|l|}{ Asia } \\
\hline East Asia & 5 & $73,792(149,993)$ & $1446(2709)$ & $37.8(6.1)$ & $32.5(5.5)$ & $34.5(6.7)$ \\
\hline North Asia (Russia) & 1 & $23,959(5463)$ & $571(107)$ & $30.9(1.8)$ & $26.7(2.5)$ & $42.1(14.8)$ \\
\hline Central Asia & 5 & $12,458(9356)$ & $118(66)$ & $33.2(3.3)$ & $28.6(3.1)$ & $30.7(3.3)$ \\
\hline West Asia & 16 & $11,225(16,228)$ & $340(789)$ & $34.2(6.3)$ & $29.1(4.5)$ & $29.9(4.8)$ \\
\hline South Asia & 8 & $330,970(605,292)$ & $12,618(23,035)$ & $38.5(6.3)$ & $33.5(5.9)$ & $36.5(7.7)$ \\
\hline Southeast Asia & 11 & $38,593(52,828)$ & $1622(2672)$ & 41.5 (6.6) & $30.9(3.9)$ & $31.9(6.1)$ \\
\hline \multicolumn{7}{|l|}{ Europe } \\
\hline Eastern Europe & 12 & $2008(2358)$ & $30(36)$ & $31.8(2.0)$ & $26.1(2.1)$ & $29.2(2.9)$ \\
\hline Northern Europe & 13 & $6925(14,182)$ & $303(674)$ & $31.8(3.0)$ & $26.2(5.1)$ & $29.9(7.1)$ \\
\hline Southern Europe & 6 & $1551(1298)$ & $23(26)$ & $30.8(3.4)$ & $24.5(2.7)$ & $25.9(3.2)$ \\
\hline Western Europe & 16 & $2905(9610)$ & $131(452)$ & $32.9(2.8)$ & $27.7(2.7)$ & $28.8(3.2)$ \\
\hline \multicolumn{7}{|l|}{ Oceania } \\
\hline $\begin{array}{l}\text { Australia and New } \\
\text { Zealand }\end{array}$ & 2 & $901(529)$ & $14(6)$ & $24.3(0.7)$ & $19.9(0.6)$ & $21.8(1.5)$ \\
\hline Melanesia & 5 & $10,957(15,496)$ & $490(728)$ & $30.8(3.6)$ & $24.4(2.8)$ & $25.2(2.7)$ \\
\hline Micronesia & 6 & $13,386(18,901)$ & $644(878)$ & $34.8(0.0)$ & $28.3(0.0)$ & $29.6(0.0)$ \\
\hline Polynesia & 5 & $16,022(19,682)$ & $763(917)$ & $34.7(0.0)$ & $28.2(0.0)$ & $29.5(0.0)$ \\
\hline
\end{tabular}

Table 1. Descriptive statistics of under-five mortality, maternal mortality, and ambient $\mathrm{PM}_{2.5}$ types by region. $n$ Number, SD Standard deviation.

local economic activity, and the effects can be reduced only when appropriate health and safety measures and environmental control strategies are considered, such as using dust masks, increasing the vegetation cover, and designing buildings appropriately.

We also found no relationship between anthropogenic $\mathrm{PM}_{2.5}$ and under-five mortality using the randomeffects model (Fig. 2a). There was only an $11.2 \%$ increase in the risk of under-five deaths in the Americas region, but this increase was not statistically significant. This finding may be possibly explained by the assumption that under-five children spend much of their time indoors, unlike adults. Notwithstanding this reason, other possible confounders and limitations of actual exposure measurements may help in explaining the results.

The global estimates, however, indicated a lack of association between different types of ambient $\mathrm{PM}_{2.5}$ and maternal deaths (Fig. 3), except for a positive relationship between biomass $\mathrm{PM}_{2.5}$ and maternal deaths in Asia (Fig. 3b), with a $4.3 \%$ increased risk of death. Most mothers from low-income households use biomass fuel for their daily cooking and thus have an increased risk of exposure to biomass $\mathrm{PM}_{2.5}{ }^{20-22}$. It is therefore imperative to think that most maternal deaths are clinically related, which would then require clinical solutions to maternal deaths. It is still important to adequately estimate how much of these deaths are contributed by $\mathrm{PM}_{2.5}$.

Finally, to estimate the dose-response relationship between the discriminated ambient $\mathrm{PM}_{2.5}$ and the underfive and maternal mortality, we used a generalized additive mixed-effects model (GAMM) with a random-effect estimation procedure (Methods). Since estimations of the dose-response relationship for global data may not be linear, the penalized spline smoothing function was used to determine the non-linear relationship between the discriminated ambient $\mathrm{PM}_{2.5}$ and the under-five and maternal mortality (Figs. 4, 5, 6, 7, 8, 9). However, the results on the dose-response relationship of the global biomass $\mathrm{PM}_{2.5}$ and the under-five mortality and maternal mortality indicated a slight increase in the risk of under-five deaths (Fig. 8) and maternal deaths (Fig. 8) after surpassing a biomass $\mathrm{PM}_{2.5}$ concentration of approximately $33 \mu \mathrm{g} / \mathrm{m}^{3}$, suggesting higher levels of exposure than the current global standards, which require daily exposure to be less than $25 \mu \mathrm{g} / \mathrm{m}^{3}$ while annual exposure should be less than $\leq 10 \mu \mathrm{g} / \mathrm{m}^{3}$. In our analyses, however, we were unable to determine the global no-threshold levels for air quality standards because of the nonlinearity of the data. Consequently, discussions of global standards and 


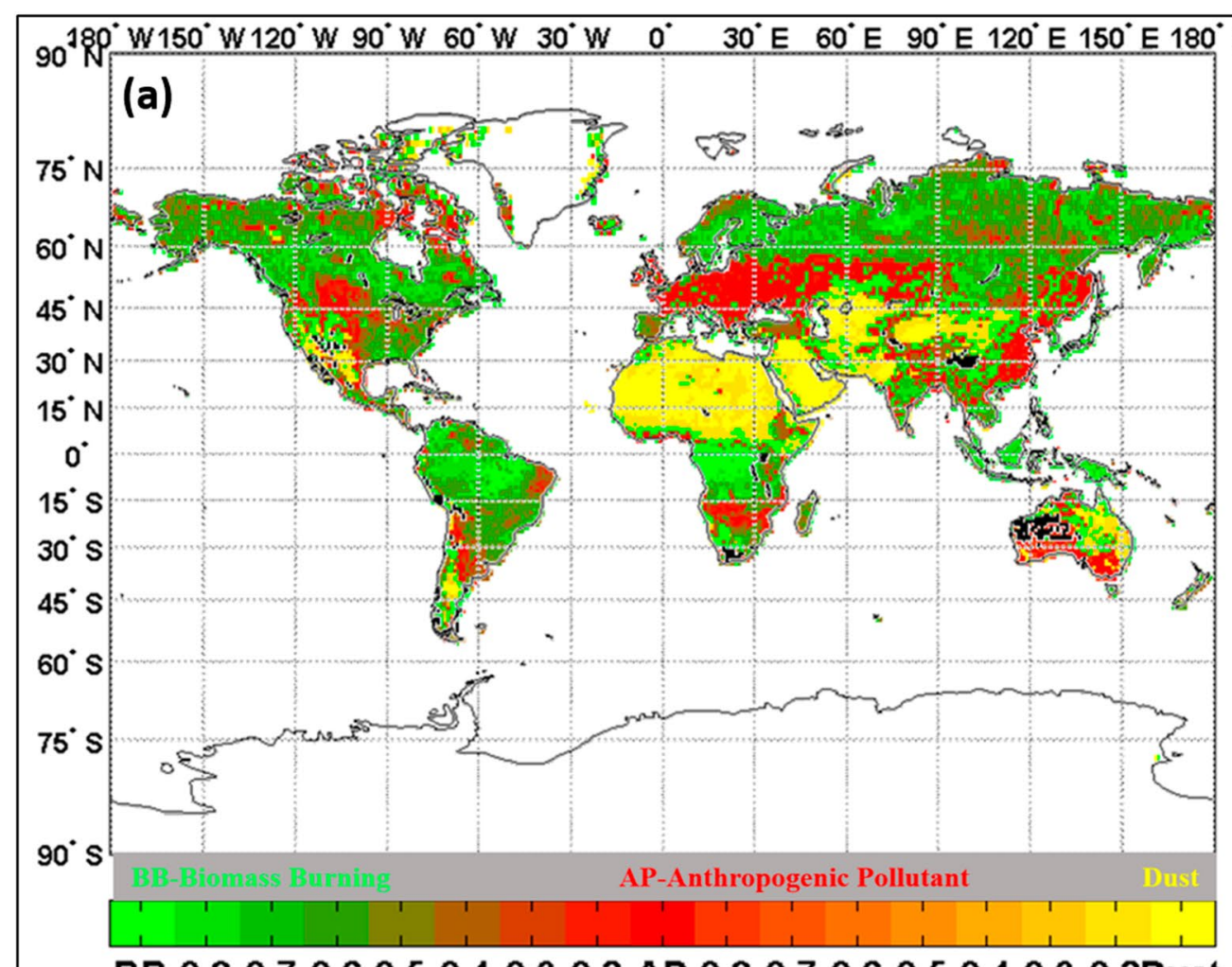

BB $0.8 \quad 0.7 \quad 0.6 \quad 0.5 \quad 0.4 \quad 0.3 \quad 0.2$ AP $0.8 \quad 0.7 \quad 0.6 \quad 0.5 \quad 0.4 \quad 0.3 \quad 0.2$ Dust

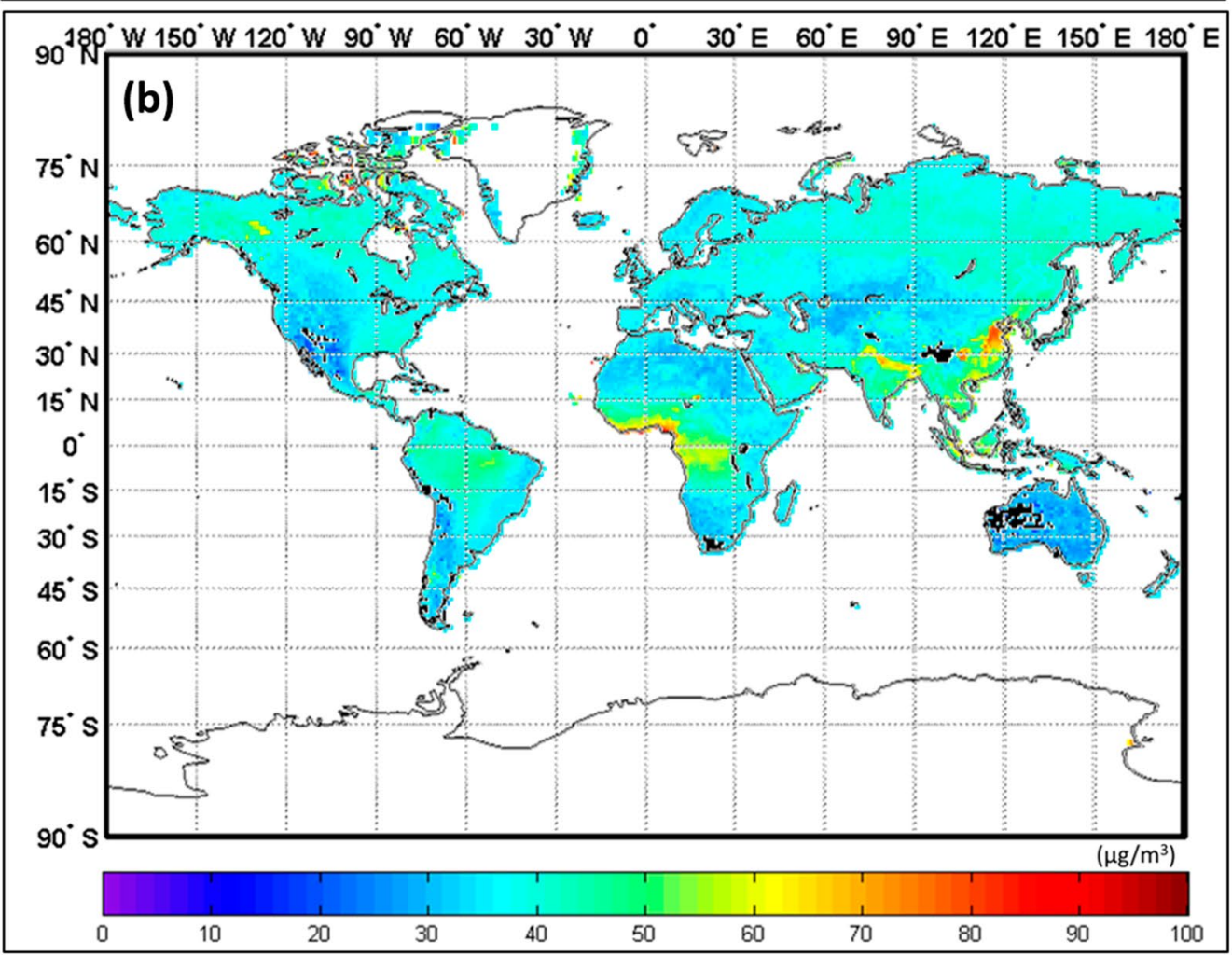

Figure 1. Spatial patterns of frequency and concentration of different $\mathrm{PM}_{2.5}$ types globally for 2000-2015. (a) Long-term frequency of $\mathrm{PM}_{2.5}$ types with fractions. (b) Long-term average $\mathrm{PM}_{2.5}$ concentration $\left(\mu \mathrm{g} / \mathrm{m}^{3}\right)$ for 2000-2015. The regions of colour in black indicate data absent. (The maps are produced by probability density function of MATLAB (matrix laboratory) software package, version 7.0, https://www.mathworks.com/products/ matlab.html). 
(a) ANTHROPOGENIC PM2.5 - UNDER-5 DEATH

Africa

Americas

Asia

Europe

Oceania

Fixed effect model

Random effect model

Heterogeneity: $I^{2}=70 \%, p<0.01$

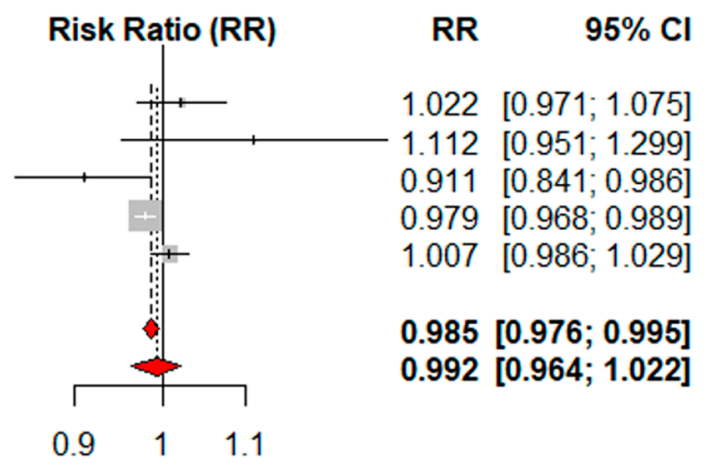

(b)

\begin{tabular}{|c|c|c|c|c|}
\hline BIOMASS PM2.5 - UNDER-5 DEATH & & Risk Ratio (RR) & $\mathbf{R} \mathbf{R}$ & $95 \% \mathrm{Cl}$ \\
\hline Africa & & & 1.012 & {$[1.012 ; 1.012]$} \\
\hline Americas & & & 1.260 & {$[1.095 ; 1.450]$} \\
\hline Asia & & & 1.486 & {$[1.383 ; 1.597]$} \\
\hline Europe & & ti & 1.008 & {$[0.994 ; 1.022]$} \\
\hline Oceania & & $\frac{1}{11}$ & 1.003 & {$[0.983 ; 1.024]$} \\
\hline Fixed effect model & & & 1.012 & {$[1.012 ; 1.012]$} \\
\hline Random effect model & & $\dot{0}$ & 1.089 & {$[1.041 ; 1.139]$} \\
\hline Heterogeneity: $I^{2}=97 \%, p<0.01$ & 075 & 1.25 & & \\
\hline
\end{tabular}

(c)

DUST PM2.5 - UNDER-5 DEATH

Africa

Americas

Asia

Europe

Oceania

Fixed effect model

Random effect model

Heterogeneity: $I^{2}=100 \%, p<0.01$

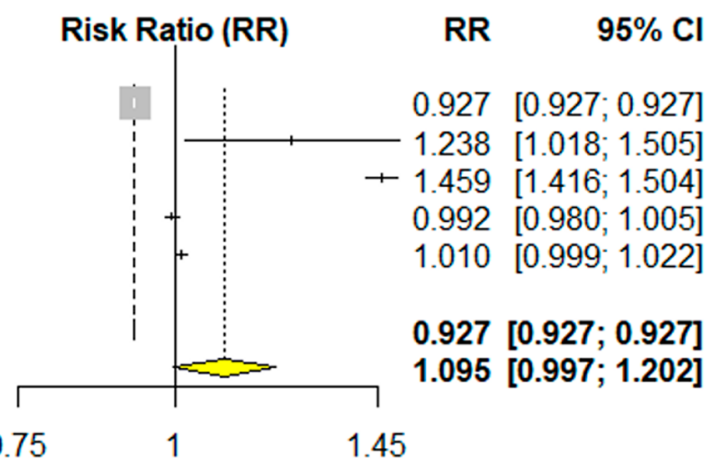

Figure 2. Forest plot of the risk of under-five deaths from (a) anthropogenic $\mathrm{PM}_{2.5}$, (b) biomass $\mathrm{PM}_{2.5}$ and (c) dust $\mathrm{PM}_{2.5}$ throughout the world.

further research are still necessary if revisions are to be made. Moreover, the populations in different regions might also have developed a stronger immune response and resilience to several hazardous elements, thereby increasing the no-threshold limit; this hypothesis warrants more tests and discussions.

Our study has several limitations and strengths. One major limitation is in our study design, which is linked to ecological fallacy-this limits our findings to an aggregate, which cannot be deduced or inferred to an individual. Future studies focused on several high-risk populations and individuals are important to extend the findings of this study. Secondly, we were unable the to classify the $\mathrm{PM}_{2.5}$-specific mortality, and the use of all-cause mortality is a major limitation in the outcome indicator. Some of the deaths in different countries might have been linked to either clinical or non-clinical factors that are not environmentally-related. This may limit causality. It is therefore necessary that future studies be aligned to cause-specific mortality which can then generate the ambient 


\begin{tabular}{|c|c|c|}
\hline \multirow[b]{2}{*}{ Variable } & \multicolumn{2}{|c|}{ Adjusted incidence rate ratio $(95 \% \mathrm{CI})^{\mathrm{a}, \mathrm{b}}$} \\
\hline & Under-5 mortality & Maternal mortality \\
\hline \multicolumn{3}{|c|}{ Anthropogenic $\mathrm{PM}_{2.5}$} \\
\hline Africa & $1.022(0.971,1.075)$ & $1.042(0.992,1.094)$ \\
\hline Americas & $1.112(0.952,1.299)$ & $1.006(0.949,1.066)$ \\
\hline Asia & $0.911(0.841,0.986)^{*}$ & $0.838(0.813,0.864)^{* * *}$ \\
\hline Europe & $0.979(0.968,0.989)^{\star * *}$ & $0.992(0.980,1.004)$ \\
\hline Oceania & $1.007(0.986,1.029)$ & $0.998(0.942,1.015)$ \\
\hline \multicolumn{3}{|c|}{ Biomass $\mathrm{PM}_{2.5}$} \\
\hline Africa & $1.012(1.012,1.012)^{\star * *}$ & $0.971(0.925,1.020)$ \\
\hline Americas & $1.260(1.095,1.450)^{\star * *}$ & $1.015(0.960,1.074)$ \\
\hline Asia & $1.486(1.383,1.597)^{\star * *}$ & $1.043(1.043,1.043)^{* * *}$ \\
\hline Europe & $1.008(0.994,1.022)$ & $1.028(0.939,1.125)$ \\
\hline Oceania & $1.003(0.983,1.024)$ & $0.937(0.907,0.968)^{\star * *}$ \\
\hline \multicolumn{3}{|c|}{ Dust $\mathrm{PM}_{2.5}$} \\
\hline Africa & $0.928(0.928,0.928)^{\star * *}$ & $0.955(0.923,0.988)^{* *}$ \\
\hline Americas & $1.238(1.018,1.506)^{\star *}$ & $0.976(0.887,1.063)$ \\
\hline Asia & $1.460(1.417,1.506)^{\star * *}$ & $0.898(0.898,0.898)^{\star * *}$ \\
\hline Europe & $0.992(0.980,1.005)$ & $1.005(0.933,1.082)$ \\
\hline Oceania & $1.010(0.999,1.022)$ & $1.022(1.000,1.044)$ \\
\hline
\end{tabular}

Table 2. Adjusted incidence rate ratios of under-five deaths and maternal deaths. CI confidence interval. ${ }^{\star} p \leq 0.05 ;{ }^{* *} p \leq 0.01 ;{ }^{* *} p \leq 0.001$. ${ }^{\mathrm{a}}$ In one unit increments of $\mathrm{PM}_{2.5}$ concentration. ${ }^{\mathrm{b}}$ Generalized linear mixedeffects models (GLMM) random-effect is used with natural cubit spline for smoothing.

$\mathrm{PM}_{2.5}$-specific death point estimates. Thirdly, there are other individual and environment factors that we were unable to control for in this study such as demographic characteristics of individuals, precipitation and humidity. These potential confounders were not controlled for because of data limitations. Several studies that would identify and collect several potential confounders are very important. Lastly, the individual level of exposure to $\mathrm{PM}_{2.5}$ cannot be adequately determined in this study, and hence it is one of the limitation towards obtaining the true dose-response relationship. There is need of an accurate exposure assessment in a follow-up study so that an accurate dose-response relationship can be determined. Our result should, therefore, be interpreted with a lot of caution since this study only determined a temporal causality.

However, our study had several strengths. First, this is the first study to investigate the link between ambient $\mathrm{PM}_{2.5}$ and the global maternal and under-five deaths. Second, the analytical strategy used in this study is very comprehensive. Advanced parametric and nonparametric analytical techniques were used to analyze the data. Estimation of dose-response relationship associated with ambient $\mathrm{PM}_{2.5}$ exposures is a major challenge for researchers because of its nonlinearity ${ }^{23}$. Our study used these two approaches to assess the effect of ambient $\mathrm{PM}_{2.5}$ in a linear and nonlinear approaches. Finally, the spatial domain in this study covered the entire world wide which is important towards understanding the global effect of ambient $\mathrm{PM}_{2.5}$.

\section{Conclusions}

Our study estimated the effects of discriminated ambient $\mathrm{PM}_{2.5}$ on the death of the under-five children and their mothers, using the global data of all the countries from different regions of the world, unlike others ${ }^{3-5}$. The $\mathrm{PM}_{2.5}$ from biomass was associated with the global under-five mortality. Close to two decades of satellite and mortality measurements in each country made it possible to estimate the effect of chronic exposure to various types of ambient $\mathrm{PM}_{2.5}$ on Earth. Our results suggest that poor air quality is a contributor to global under-five deaths and that appropriate air monitoring techniques and intervention strategies should be put in place to reduce the global burden of disease. It is also of great importance to determine the actual deaths that are attributable to $\mathrm{PM}_{2.5}$ to enable a conclusive determination of the no-threshold limits for different regions and, subsequently, the global air quality standards.

With the new development of remote sensing technology for aerosol portioning, the global impacts of discriminated $\mathrm{PM}_{2.5}$ on under-five and maternal mortality are carefully examined for the first time using satellite observations. The results illustrated that the different sensitivity of under-five and maternal mortality to the types of $\mathrm{PM}_{2.5}$ in regional shown in Figs. 2 and 3 and highly correspondent with the $\mathrm{PM}_{2.5}$ concentration as Fig. $1 \mathrm{~b}$ demonstrated in the regions of Asia and Africa. This research represents a significant advance in public health science related to species of air pollution in daily life, which is currently one of the greatest global issues.

\section{Methods}

Spatial domain. The spatial domain included 206 countries and islands that were listed according to the ISO 3166 list of countries maintained by the International Organization of Standardization (Table 3). These countries were grouped according to different geographical locations for our analyses. 
(a)

ANTHROPOGENIC PM2.5 - MATERNAL DEATH

Africa

Americas

Asia

Europe

Oceania

Fixed effect model

Random effect model

Heterogeneity: $I^{2}=95 \%, p<0.01$

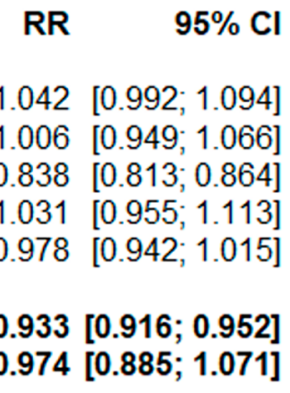

$1.042[0.992 ; 1.094]$

$1.006[0.949 ; 1.066]$

$0.838[0.813 ; 0.864]$

$1.031[0.955 ; 1.113]$

$0.978[0.942 ; 1.015]$

$0.933[0.916 ; 0.952]$

$0.974[0.885 ; 1.071]$

(b)

BIOMASS PM2.5 - MATERNAL DEATH

Africa

Americas

Asia

Europe

Oceania

Fixed effect model

Random effect model

Heterogeneity: $I^{2}=92 \%, p<0.01$

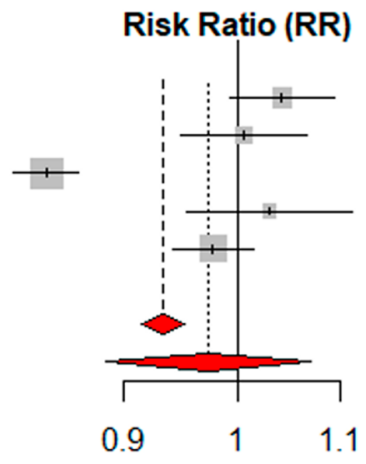

$\begin{array}{lll}0.9 & 1 & 1.1\end{array}$

\section{(1)}



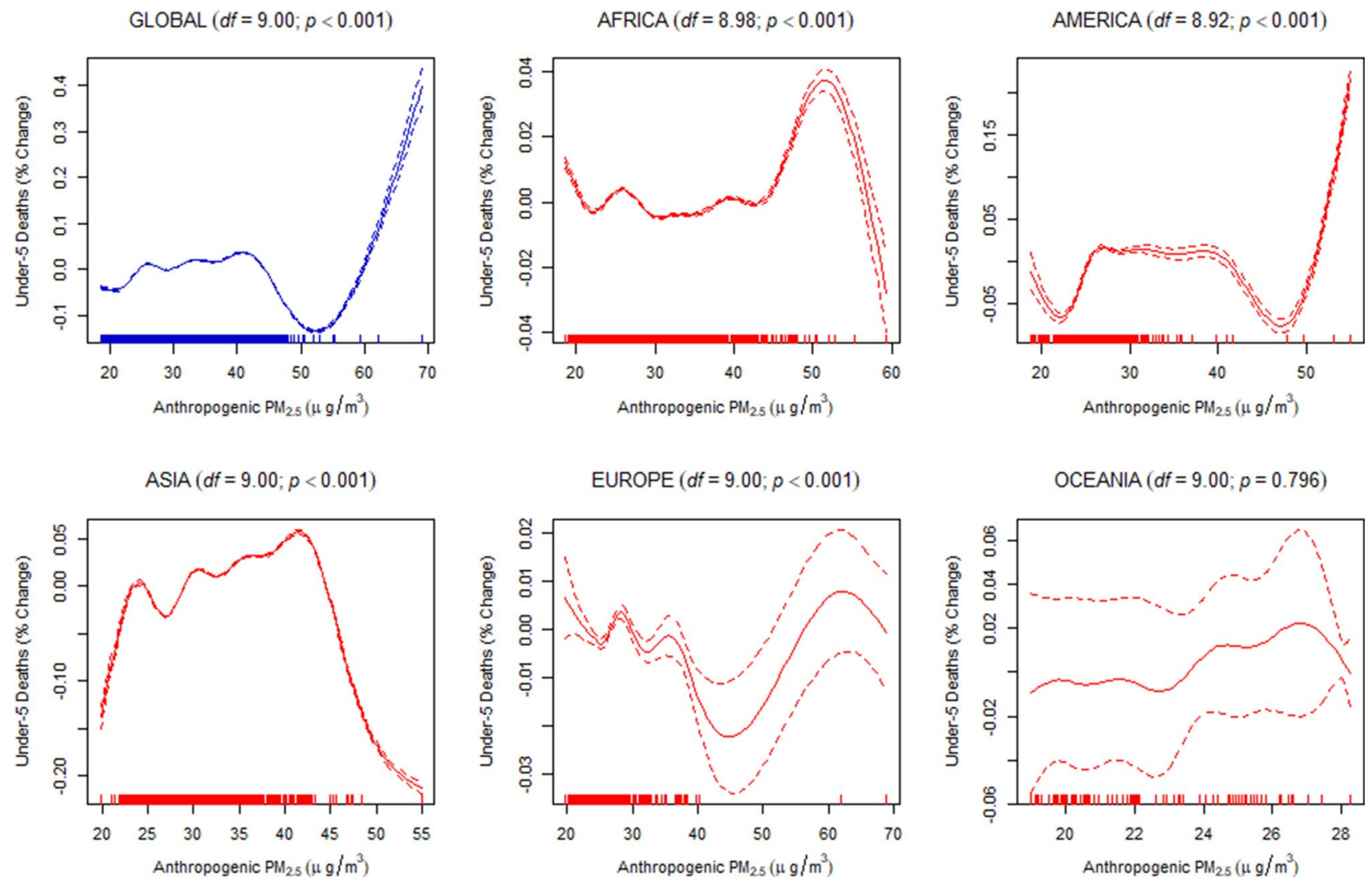

Figure 4. Penalized spline of anthropogenic $\mathrm{PM}_{2.5}$ and under-five deaths by region.
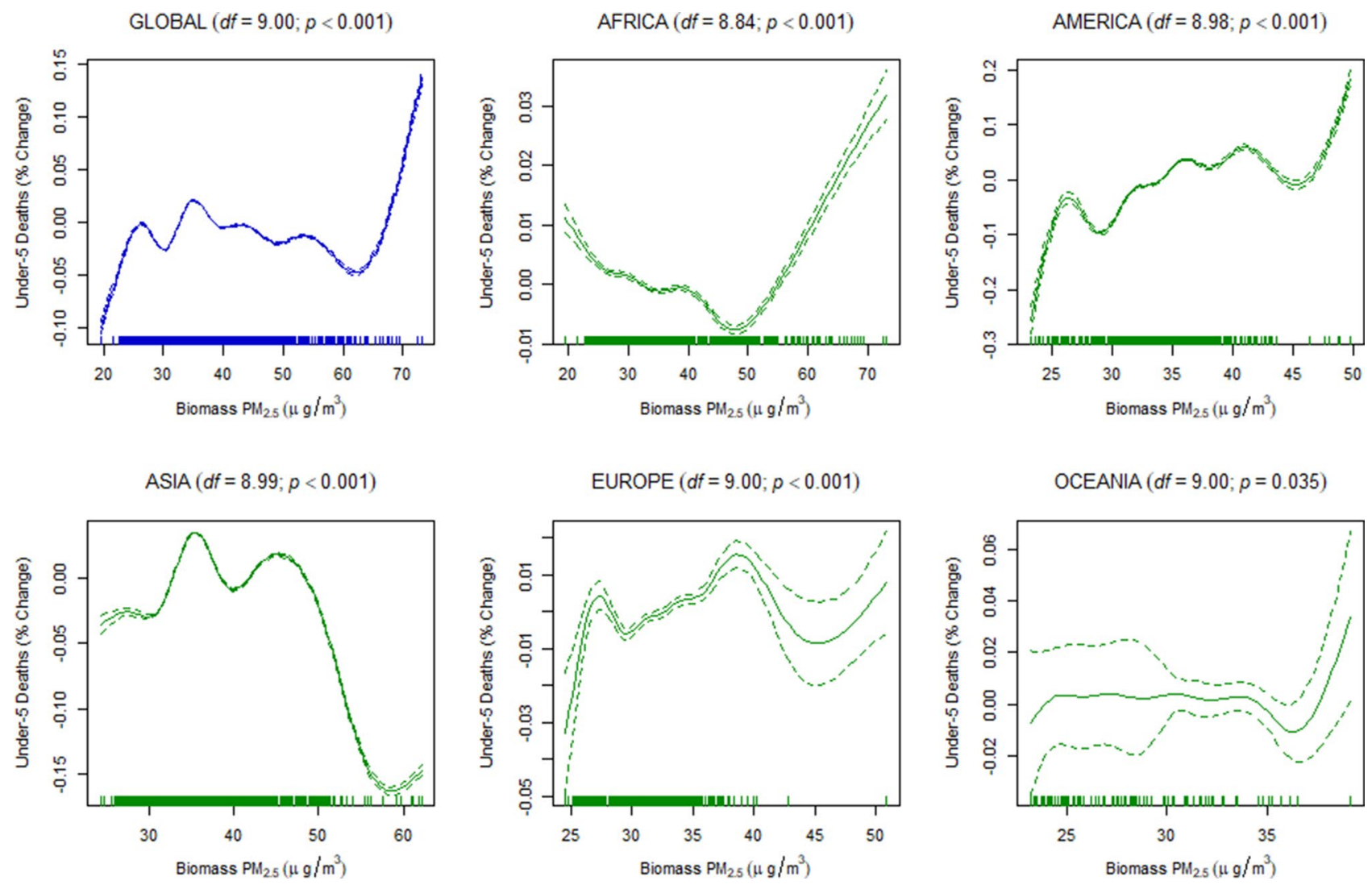

Figure 5. Penalized spline of biomass $\mathrm{PM}_{2.5}$ and under-five deaths by region. 

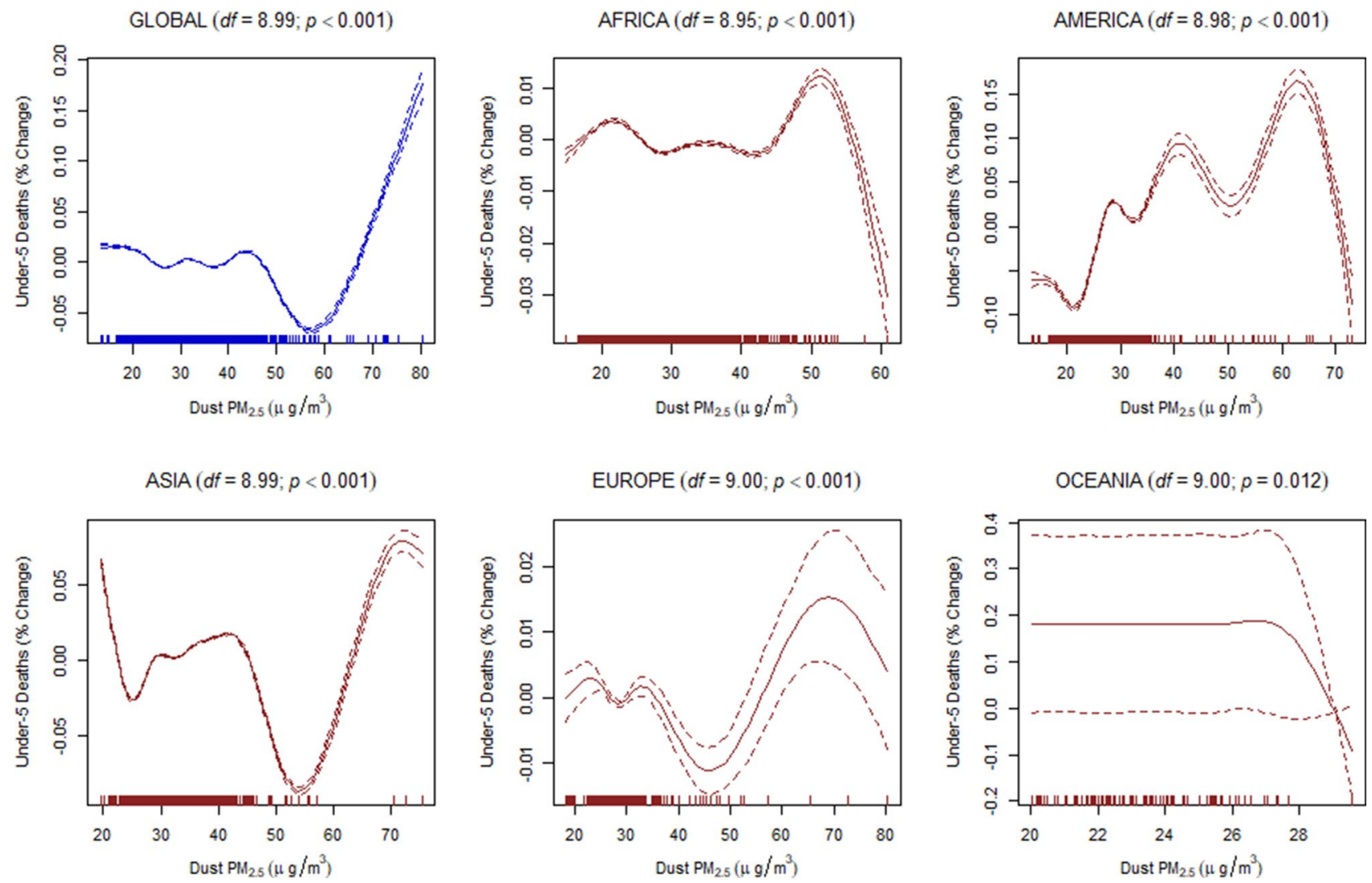

Figure 6. Penalized spline of dust $\mathrm{PM}_{2.5}$ and under-five deaths by region.

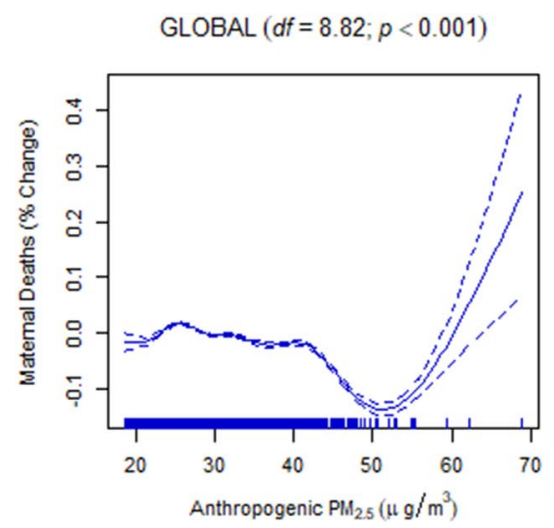

$\operatorname{ASIA}(d f=7.92 ; p<0.001)$

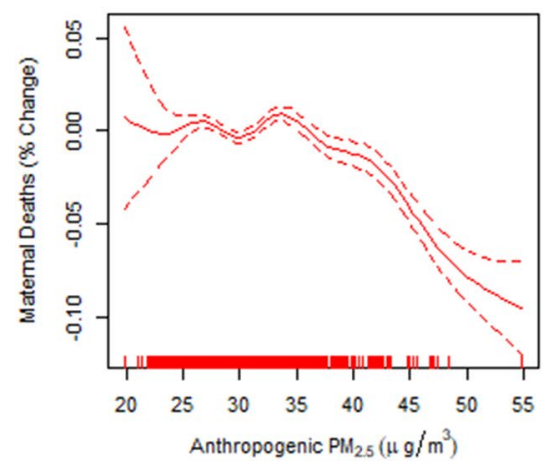

$\operatorname{AFRICA}(d f=8.78 ; p<0.001)$

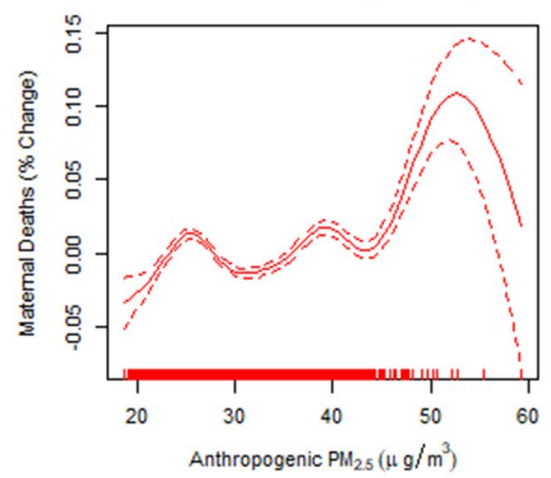

EUROPE $(d f=9.00 ; p=0.072)$

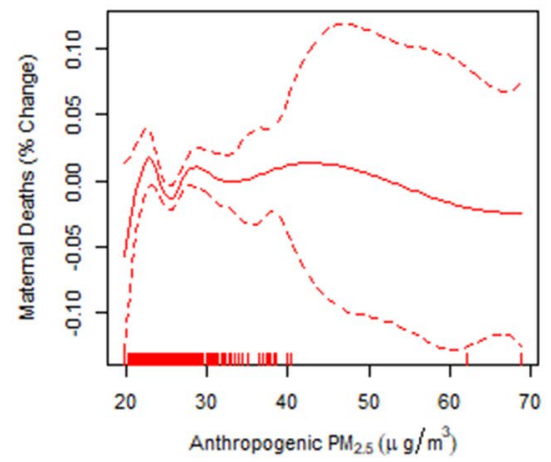

AMERICA $(d f=4.65 ; p=0.020)$

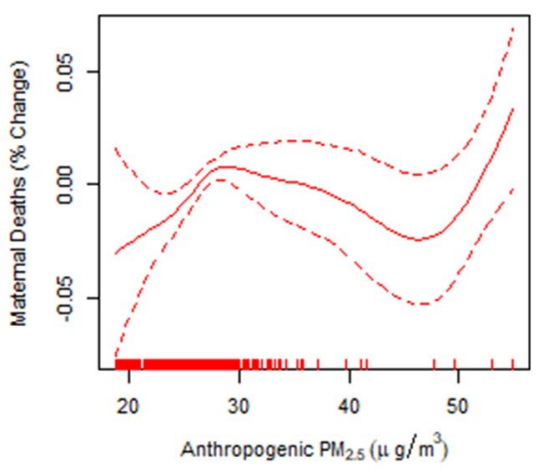

OCEANIA $(d f=9.00 ; p<0.001)$

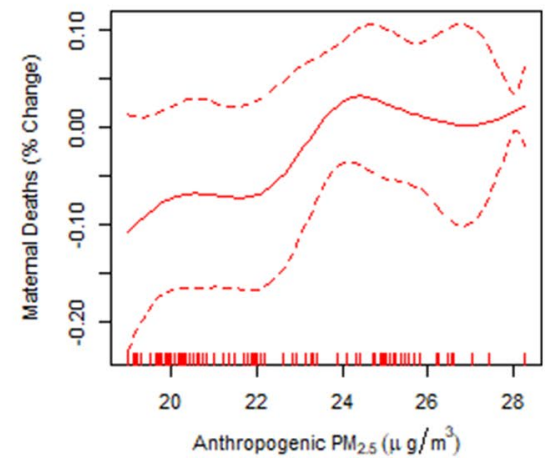

Figure 7. Penalized spline of anthropogenic $\mathrm{PM}_{2.5}$ and maternal deaths by region. 


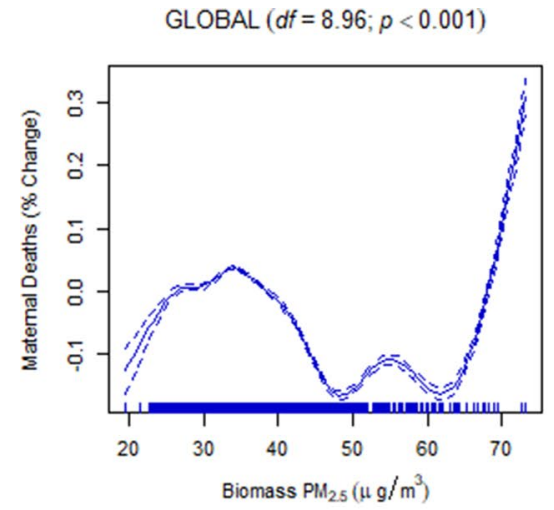

$\operatorname{ASIA}(d f=8.50 ; p<0.001)$

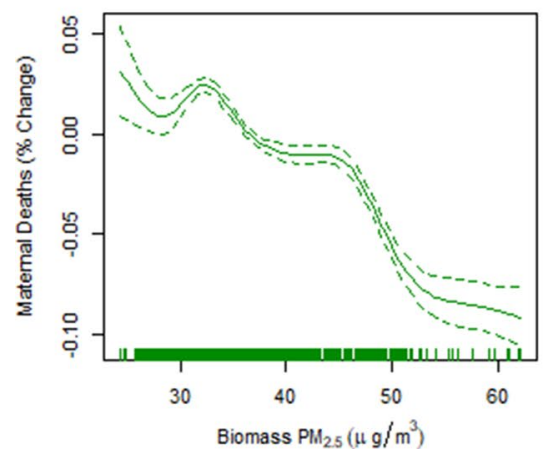

$\operatorname{AFRICA}(d f=8.9 ; p<0.001)$

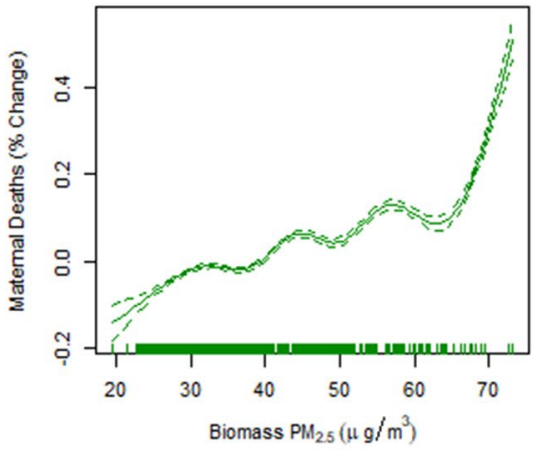

EUROPE $(d f=9.00 ; p=0.732)$

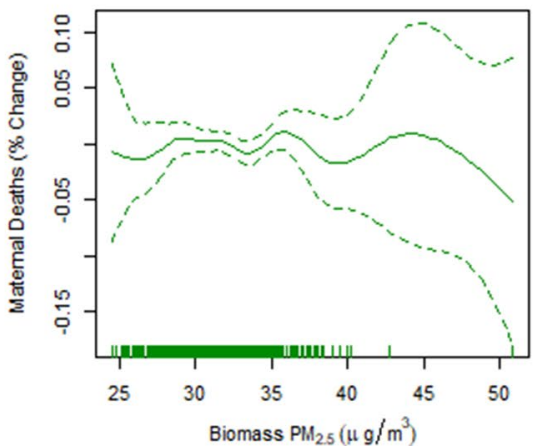

$\operatorname{AMERICA}(d f=6.32 ; p<0.001)$

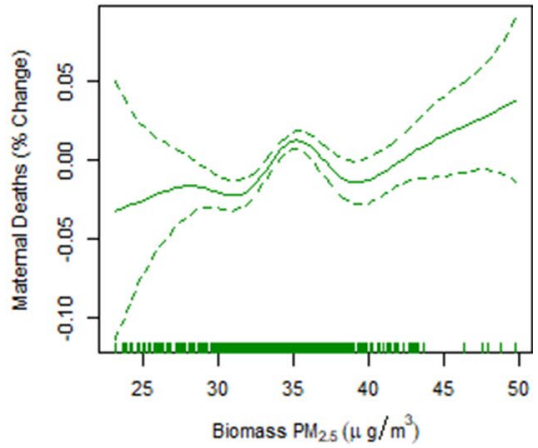

OCEANIA $(d f=5.76 ; p<0.001)$

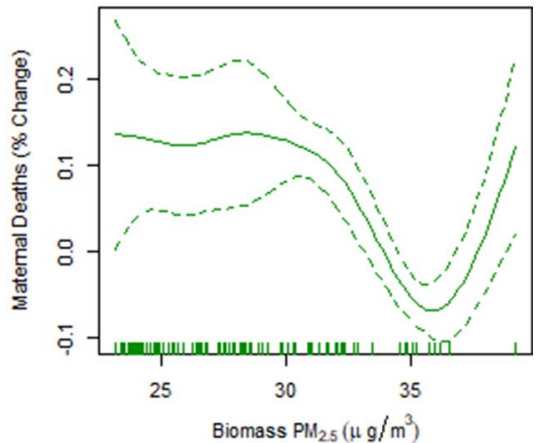

Figure 8. Penalized spline of biomass $\mathrm{PM}_{2.5}$ and maternal deaths by region.

$\operatorname{GLOBAL}(d f=8.89 ; p<0.001)$

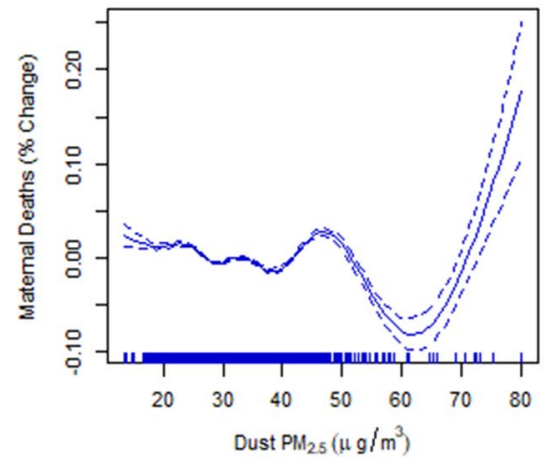

$\operatorname{ASIA}(d f=8.61 ; p<0.001)$

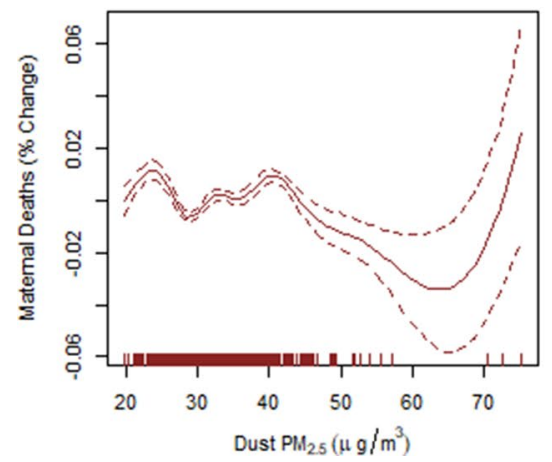

$\operatorname{AFRICA}(d f=8.69 ; p<0.001)$

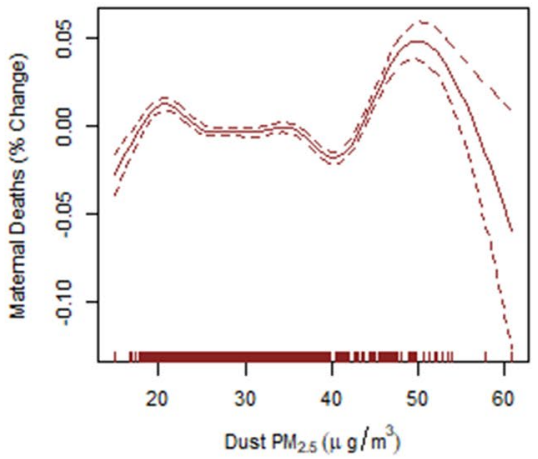

EUROPE $(d f=9.00 ; p=0.132)$

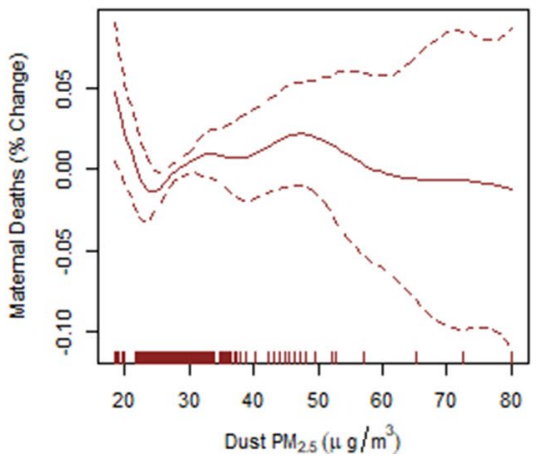

$\operatorname{AMERICA}(d f=6.80 ; p=0.050)$

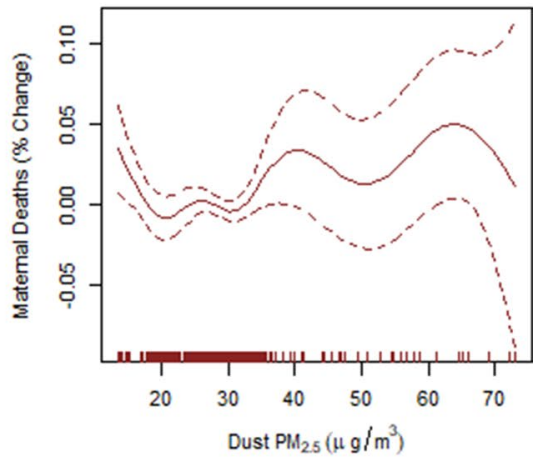

$\operatorname{OCEANIA}(d f=9.00 ; p<0.001)$

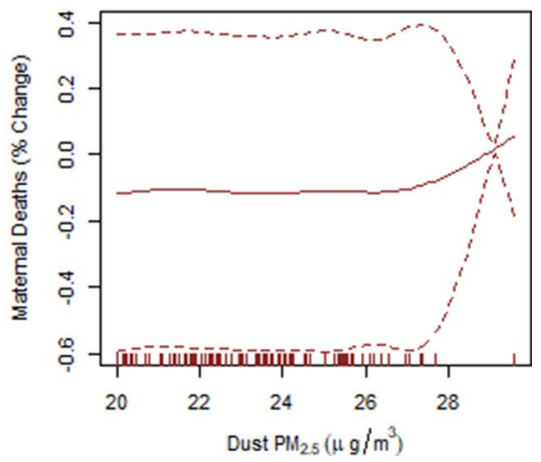

Figure 9. Penalized spline of dust $\mathrm{PM}_{2.5}$ and maternal deaths by region. 


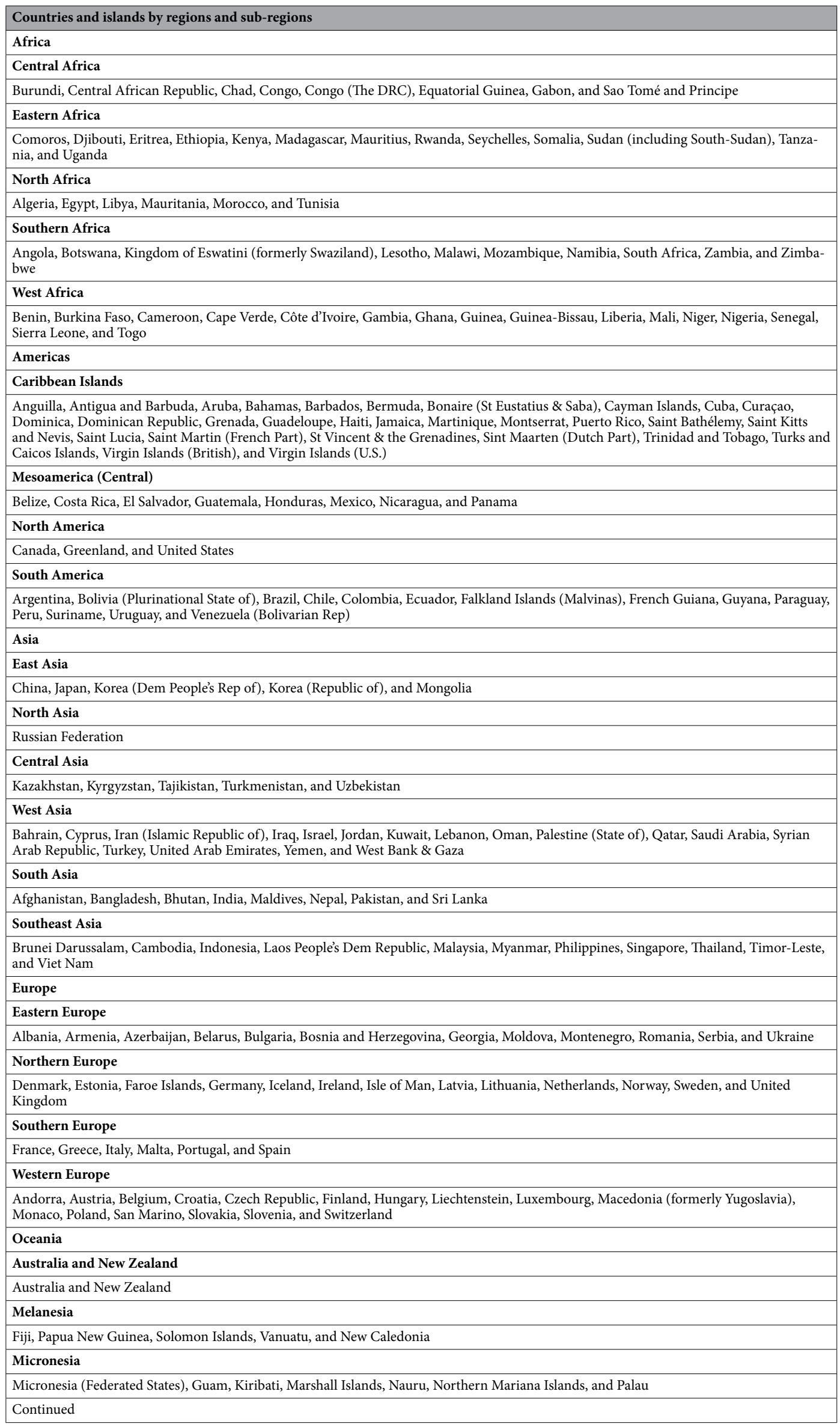


Table 3. List of countries following the ISO 3166 list of countries and islands maintained by the International Organization of Standardization, assigned to each geographical region.

explained in one study ${ }^{26}$ and applied in another ${ }^{5}$. The optical properties of particle size distribution and single scattering albedo (absorption and scattering) are important to distinguish between aerosol types, while the concentrations were calculated using the AOD- $\mathrm{PM}_{2.5}$ association for each type of aerosol ${ }^{27}$. The $\mathrm{PM}_{2.5}\left(\mu \mathrm{g} / \mathrm{m}^{3}\right)$ types were generated using the following formulas ${ }^{27}$ :

$$
\begin{gathered}
P M_{2.5}^{\text {Biomass }}=98.3 \times A O D_{660 \mathrm{~nm}}+15.4 ; \\
P M_{2.5}^{\text {Anthropogenic }}=62.4 \times A O D_{660 \mathrm{~nm}}+12.4 ; \text { and } \\
P M_{2.5}^{\text {Dust }}=52.8 \times A O D_{660 \mathrm{~nm}}+9.68 .
\end{gathered}
$$

Potential confounders. The following country-level variables from 2000 to 2015 were used to adjust our model: total number of undernourished, anaemic pregnant women, tuberculosis cases, AIDS deaths, employed, females, population in urban areas, year, country and country's annual mean temperature. All the data were extracted from the World Bank's database ${ }^{24}$.

Statistical treatment. After data cleaning, our data were analysed in several stages. First, the monthly $\mathrm{PM}_{2.5}$ concentrations were used to generate the annual average concentrations for each country and subsequently for each region. The annual mean mortality and types of $\mathrm{PM}_{2.5}$ are presented for each region (Table 1). Second, data were analysed using the penalized quasi-likelihood (PQL) approach in the generalized linear mixed-effects model (GLMM) with a spatial covariance structure and the Poisson link function to obtain the adjusted incident rate ratio (IRR) for each region (Table 2). A natural cubic spline was employed for the smoothing effect while specifying the country and year as the random effects since both the outcome and the exposure were dispersed and correlated over time and across boundaries ${ }^{28}$. We also considered spatial variations by employing a spatial covariance structure in our analyses. Third, a meta-analysis approach was used to determine the global estimates of the adjusted risk of death as a result of the $\mathrm{PM}_{2.5}$ types (Figs. 2, 3). Finally, the dose-response relationship was determined using the penalized spline and the generalized additive mixed-effects model (GAMM), and year and country were taken as the random effects because of the nonparametric relationship that was exhibited in the global data (Figs. 4, 5, 6, 7, 8, 9). The degrees of freedom were estimated using generalized cross-validation $(\mathrm{GCV})$. We stratified all our analyses by different geographical regions in the world. The GAMM accounts for the over-dispersion and correlation in an additive non-linear approach, as it considers the random effects in the additive predictor. Moreover, GAMM also uses nested and crossed designs to analyse spatial, clustered and hierarchical data ${ }^{28}$. R version 3.6.0 $0^{29}$ software and Stata version $13.0^{30}$ were used in our analyses. Data were then presented in the forms of tables and figures.

\section{Data availability}

Mortality data used for our analyses are available from the World Bank databank (databank.worldbank.org) while the $\mathrm{PM}_{2.5}$ data were extracted from the MODIS aerosol optical depth satellite products (https://modis.gsfc.nasa. gov/data/dataprod/mod04.php).

Received: 4 February 2020; Accepted: 7 September 2020

Published online: 19 October 2020

\section{References}

1. World Health Organization. Maternal mortality, https://www.who.int/news-room/fact-sheets/detail/maternal-mortality (2019).

2. World Health Organization. Under-five mortality, https://www.who.int/gho/child_health/mortality/mortality_under_five_text/ en/ (2019).

3. Cohen, A. J. et al. Estimates and 25-year trends of the global burden of disease attributable to ambient air pollution: An analysis of data from the Global Burden of Diseases Study 2015. Lancet 389, 1907-1918. https://doi.org/10.1016/S0140-6736(17)30505-6 (2017).

4. Heft-Neal, S., Burney, J., Bendavid, E. \& Burke, M. Robust relationship between air quality and infant mortality in Africa. Nature 559, 254-258. https://doi.org/10.1038/s41586-018-0263-3 (2018).

5. Owili, P., Lien, W.-H., Muga, M. \& Lin, T.-H. The associations between types of ambient PM2.5 and under-five and maternal mortality in Africa. Int. J. Environ. Res. Public Health 14, 359 (2017).

6. Lelieveld, J., Evans, J. S., Fnais, M., Giannadaki, D. \& Pozzer, A. The contribution of outdoor air pollution sources to premature mortality on a global scale. Nature 525, 367-371. https://doi.org/10.1038/nature15371 (2015).

7. Lien, W.-H., Owili, P. O., Muga, M. A. \& Lin, T.-H. Ambient particulate matter exposure and under-five and maternal deaths in Asia. Int. J. Environ. Res. Public Health 16, 3855 (2019). 
8. Lee, P. K., Brook, J. R., Dabek-Zlotorzynska, E. \& Mabury, S. A. Identification of the major sources contributing to PM2.5 observed in Toronto. Environ. Sci. Technol. 37, 4831-4840 (2003).

9. Li, H. Z., Dallmann, T. R., Li, X., Gu, P. \& Presto, A. A. Urban organic aerosol exposure: Spatial variations in composition and source impacts. Environ. Sci. Technol. 52, 415-426. https://doi.org/10.1021/acs.est.7b03674 (2018).

10. Jeong, C. H. et al. Identification of the sources and geographic origins of black carbon using factor analysis at paired rural and urban sites. Environ. Sci. Technol. 47, 8462-8470. https://doi.org/10.1021/es304695t (2013).

11. Kutlar Joss, M., Eeftens, M., Gintowt, E., Kappeler, R. \& Kunzli, N. Time to harmonize national ambient air quality standards. Int. J. Public Health 62, 453-462. https://doi.org/10.1007/s00038-017-0952-y (2017).

12. You, M. Addition of PM 2.5 into the national ambient air quality standards of China and the contribution to air pollution control: the case study of Wuhan, China. Sci. World J. 2014, 768405-768405. https://doi.org/10.1155/2014/768405 (2014).

13. Lin, T.-H., Liu, G.-R. \& Liu, C.-Y. A novel index for atmospheric aerosol types categorization with spectral optical depths from satellite retrieval. ISPRS Int. Arch. Photogramm. Remote Sens. Spat. Inf. Sci. XLI-B8, 277-279. https://doi.org/10.5194/isprs-archi ves-XLI-B8-277-2016 (2016).

14. Owili, P. O., Muga, M. A., Pan, W. C. \& Kuo, H. W. Cooking fuel and risk of under-five mortality in 23 Sub-Saharan African countries: A population-based study. Int. J. Environ. Health Res. https://doi.org/10.1080/09603123.2017.1332347 (2017).

15. Naz, S., Page, A. \& Agho, K. E. Household air pollution and under-five mortality in India (1992-2006). Environ. Health 15, 54. https://doi.org/10.1186/s12940-016-0138-8 (2016).

16. Jiménez-Vélez, B., Detrés, Y., Armstrong, R. A. \& Gioda, A. Characterization of African Dust (PM2.5) across the Atlantic Ocean during AEROSE 2004. Atmos. Environ. 43, 2659-2664. https://doi.org/10.1016/j.atmosenv.2009.01.045 (2009).

17. Perez, L. et al. Coarse particles from Saharan dust and daily mortality. Epidemiology 19, 800-807 (2008).

18. Griffin, D. W., Kellogg, C. A. \& Shinn, E. A. Dust in the wind: Long range transport of dust in the atmosphere and its implications for global public and ecosystem health. Glob. Change Human Health 2, 20-33. https://doi.org/10.1023/a:1011910224374 (2001).

19. Querol, X. et al. Monitoring the impact of desert dust outbreaks for air quality for health studies. Environ. Int. 130, 104867. https ://doi.org/10.1016/j.envint.2019.05.061 (2019).

20. Piddock, K. C. et al. A cross-sectional study of household biomass fuel use among a periurban population in Malawi. Ann. Am. Thorac. Soc. 11, 915-924. https://doi.org/10.1513/AnnalsATS.201311-413OC (2014).

21. Komala, H. P. \& Prasad, A. G. D. Utilization pattern of biomass energy and socioeconomic dimensions associated with Yelandur, Karnataka, India. Int. J. Energy Environ. Eng. 5, 95. https://doi.org/10.1007/s40095-014-0095-3 (2014).

22. Gumartini, T. Biomass energy in the Asia-Pacific region: Current status, trends and future setting. https://www.fao.org/3/a-am621 e.pdf (2009).

23. Burnett, R. T. et al. An integrated risk function for estimating the global burden of disease attributable to ambient fine particulate matter exposure. Environ. Health Perspect. 122, 397-403. https://doi.org/10.1289/ehp.1307049 (2014).

24. World Bank. World Development Indicators, https://databank.worldbank.org/data/home.aspx (2016).

25. Levy, R. \& Hsu, C. MODIS Atmosphere L2 Aerosol Product. (NASA MODIS Adaptive Processing System, 2015).

26. Lin, T.-H., Liu, G.-R. \& Liu, C.-Y. A novel index for atmospheric aerosol type categorization with spectral optical depths from satellite retrieval. Int. Arch. Photogramm. Remote Sens. Spat. Inf. Sci. 8, 277-279. https://doi.org/10.5194/isprs-archives-XLI-B8-277-2016 (2016).

27. Sano, I., Mukai, M., Iguchi, N. \& Mukai, S. Suspended particulate matter sampling at an urban AERONET site in Japan, part 2: Relationship between column aerosol optical thickness and PM2.5 concentration. APPRES. https://doi.org/10.1117/1.3327930 (2010).

28. Lin, X. \& Zhang, D. Inference in generalized additive mixed modelsby using smoothing splines. J. R. Stat. Soc. Ser. B (Stat. Methodol.) 61, 381-400. https://doi.org/10.1111/1467-9868.00183 (1999).

29. R Core Team. R: A language and environment for statistical computing. https://www.R-project.org/ (2013).

30. StataCorp. Stata Statistical Software: Release 13. (StataCorp LP, 2013).

\section{Acknowledgements}

The authors gratefully acknowledge World Bank and Goddard Space Flight Center of National Aeronautics and Space Administration (NASA-GSFC) for the provisions of mortality data and aerosol products in global, respectively. We thank Taiwan's Ministry of Science and Technology (MOST) for financial support with Grant numbers MOST 108-2111-M-008-024 and MOST 107-2111-M-008-024.

\section{Author contributions}

P.O.O., M.A.M., W.H.L. and T.H.L. conceived the research; P.O.O. and W.H.L. extracted the data; P.O.O. analysed the data; P.O.O., M.A.M., W.H.L. and T.H.L. interpreted and wrote the paper.

\section{Competing interests}

The authors declare no competing interests.

\section{Additional information}

Correspondence and requests for materials should be addressed to T.-H.L.

Reprints and permissions information is available at www.nature.com/reprints.

Publisher's note Springer Nature remains neutral with regard to jurisdictional claims in published maps and institutional affiliations.

\footnotetext{
(c) (i) Open Access This article is licensed under a Creative Commons Attribution 4.0 International cc) License, which permits use, sharing, adaptation, distribution and reproduction in any medium or format, as long as you give appropriate credit to the original author(s) and the source, provide a link to the Creative Commons licence, and indicate if changes were made. The images or other third party material in this article are included in the article's Creative Commons licence, unless indicated otherwise in a credit line to the material. If material is not included in the article's Creative Commons licence and your intended use is not permitted by statutory regulation or exceeds the permitted use, you will need to obtain permission directly from the copyright holder. To view a copy of this licence, visit http://creativecommons.org/licenses/by/4.0/.
}

(C) The Author(s) 2020 